\title{
A micro-CT evaluation of the performance of rotary and reciprocating single-file systems in shaping ability of curved root canals
}

\author{
Manoel Damião \\ SOUSA-NETO(a) \\ Bruno Monguilhott CROZETA(a) \\ Fabiane Carneiro LOPES(a) iD \\ Jardel Francisco \\ MAZZI-CHAVES(a) ID \\ Rodrigo Dantas PEREIRA(a) iD \\ Alice Corrêa SILVA-SOUSA(a) \\ Mariana Carvalho de Andrade \\ AMARAL (b) \\ Liviu STEIER ${ }^{(c)}$ iD \\ Reinhilde JACOBS(d) \\ Yara Teresinha Corrêa \\ SILVA-SOUSA(b) iD
}

(a) Universidade de São Paulo - USP, School of Dentistry of Ribeirão Preto, Department of Restorative Dentistry, Ribeirão Preto, SP, Brazil.

(b) Universidade de Ribeirão Preto - UNAERP,

Faculty of Dentistry, Ribeirão Preto, SP, Brazil.

(c) University of Pennsylvania - UPenn, School of Dental Medicine, Philadelphia, PA, USA.

(d) Katholieke Universiteit Leuven - KU Leuven, Faculty of Medicine, Department of Imaging and Pathology, Leuven, Belgium.

Declaration of Interests: The authors certify that they have no commercial or associative interest that represents a conflict of interest in connection with the manuscript.

Corresponding Author:

Manoel Damião Sousa Neto

E-mail: sousanet@forp.usp.br

https://doi.org/10.1590/1807-3107bor-2020.vol34.0039

Submitted: Novmber 7, 2019

Accepted for publication: March 23, 2020

Last revision: March 30, 2020
Abstract: To compare the shaping ability of different single-file systems in the preparation of mesial curved canals of mandibular molars using micro-CT technology. Fifteen mesial roots of mandibular molars with two independent and curved canals $(\mathrm{n}=30)$ were selected, scanned at a resolution of $26.7 \mu \mathrm{m}$ anatomically matched, and distributed into three groups $(n=10)$, according to the preparation system: WaveOne 25.08, Reciproc 25.08, and OneShape 25.06. A final micro-CT scanning was performed, data sets were registered with their respective counterparts, and compared regarding the three-dimensional (volume, surface area, and structure model index - SMI) and two-dimensional (perimeter, area, roundness, major and minor diameters) parameters, as well as, canal transportation, using ANOVA and post hoc Tukey tests $(\alpha=5 \%)$. Overall, no difference was observed between groups regarding area, perimeter, volume, surface area, and canal transportation $(\mathrm{p}>0.05)$. Within group, no canal transportation was significantly higherobserved in the apical third $(0.10 \pm 0.05 \mathrm{~mm})$ compared to coronal $(0.08 \pm 0.040 \mathrm{~mm})$ and middle $(0.07 \pm 0.03 \mathrm{~mm})$ thirds $(p<0.05)$. Structure model index (SMI) was statistically higher after preparation with OneShape instrument $(0.36 \pm 0.26)$ compared to other systems $(\mathrm{p}<0.05)$. Within the parameters of this study, similar shaping ability was observed in the preparation of mesial curved root canals of mandibular molars with Reciproc, OneShape and WaveOne systems.

\section{Introduction}

Recent studies using micro-CT technology have shown the existence of different anatomical complexities of the root canal system in different groups of teeth including isthmus, ramifications, recesses, and curvatures. ${ }^{1,2}$ Although many technical advances have been made in endodontics with the development of nickel-titanium instruments with different designs, surface treatment and movement kinematics, ${ }^{3,4,5}$ canal preparation is still adversely influenced by the highly variable anatomy, especially in curved root canals. 5,6 The different curvature angles and the radius of the root canal are important aspects to be observed, since, during the preparation of these root canals, iatrogenic such as steps, zips, perforations, and canal 
transportation may occur, ${ }^{7,8,9}$ depending on the type of alloy and kinematics of the instrument used. ${ }^{5,7,8,9}$

With the evolution of the mechanized systems from the use of NiTi alloys, new alloys, designs, and kinematics were developed, which allowed the creation of systems that use only one instrument, optimizing the preparation of the root canals. Initially, single instrument systems with reciprocating kinematics appeared on the market, ${ }^{8,10}$ made with M-wire NiTi, changing pitch, helical angle, reverse helix, and two distinct cross-sections along the length of the active portion of the instrument. These characteristics result in greater flexibility, fracture, and fatigue resistance, which increases safety during preparation mainly in curved root canals. ${ }^{8}$ Another concept in the preparation of root canals utilizing a single instrument, but with rotational kinematics, is the OneShape system (MicroMega, Besançon, France). This system is characterized by instruments with 0.06 constant taper and different models of cross section with a changing pitch length along the working part that eliminates the threading effect and binding of the instrument in continuous rotation inside the root canal. ${ }^{11,12}$ The shaping ability and canal transportation of the single-file rotary systems has been compared with single-file reciprocating systems with encouraging results, once both techniques are able to shape curved root canals. ${ }^{11,12,13,14,15,16,17,18,19}$

In curved root canals, instrumentation is a critical step due to the difficulty of adjusting the instruments to the canal anatomy. ${ }^{16}$ Even though there is accumulating evidence of the safety, in terms of causing less ledges or transportation, and shaping effectiveness of the Reciproc and WaveOne ${ }^{14,17,20}$ knowledge of the shaping ability of OneShape in curved mandibular molars is still lacking. Moreover, a three-dimensional analysis of root canal preparation of moderately curved canals with those instruments using micro-CT is important to show the shaping ability performance of this single-file systems. Therefore, the aim of this study was to compare the shaping ability of Reciproc, WaveOne and OneShape single-file systems in the two and three-dimensional parameters during the preparation of mesial moderately curved canals of mandibular molars using micro-CT technology.

\section{Methodology}

\section{Sample size calculation}

SigmaPlot 11.0 statistical software (Systat Software Inc, San Jose, USA) was used for sample size calculation that was based on the following pre-established parameters from a pilot study: minimum detectable difference between the change percentage equal to 0.30 and coefficient of variation equal to 0.20 for volume, surface area and SMI respectively. An alpha-type error of 0.05 , power beta of 0.8 , and number of groups (within subjects) of 2 were considered. With these results, the estimated minimum sample was found to be 10 canals per group. The statistical power analysis before the experiments resulted in a value of 0.742 .

\section{Sample Selection}

Fifteen mesial roots of permanent mandibular molars were selected from a pool of teeth. The inclusion criteria were mesial roots with 2 fully formed and moderately curved independent canals (angle of curvature: $10^{\circ}$ to $20^{\circ}$; radius of curvature: 4 to $\left.8 \mathrm{~mm}\right){ }^{21}$, with no previous treatment, calcification, resorption or root fracture. Specimens were imaged using a micro-CT device (SkyScan 1174v2; Bruker-microCT, Kontich, Belgium) at $50 \mathrm{kV}, 800 \mathrm{~mA}$, isotropic resolution of $26.7 \mu \mathrm{m}$ and through $360^{\circ}$ rotation around the vertical axis with a rotation step of $1^{\circ}$, using a 0.5 -mm-thick aluminum filter. The projection images were reconstructed (NRecon v.1.6.9; Bruker micro-CT, city, country) and the volume of interest selected extending from the furcation level to the apex of the root. Then, canals $(n=30)$ were anatomically matched and assigned to 1 of the 3 experimental groups $(\mathrm{n}=10)$, according to the canal preparation systems, i.e. WaveOne, Reciproc, or OneShape. After checking the normality assumption (Shapiro-Wilk test), the degree of homogeneity (baseline) of the 3 groups with respect to volume, surface area and SMI (Table 1), was confirmed using the One-way analysis of variance test $(p>0.05)$.

\section{Root Canal preparation}

Mesial canals were accessed and apical patency was confirmed with a size 10 K-type file (Dentsply Sirona, Ballaigues, Switzerland) passed through the apical 
Table 1. Median percentage increase and interquartile range of 3-dimensional parameters measured mesial root canals of mandibular molars after preparation with the Waveone, Reciproc, and OneShape systems.

\begin{tabular}{|c|c|c|c|}
\hline \multirow{2}{*}{ 3-dimensional parameters } & \multicolumn{3}{|c|}{ Systems } \\
\hline & WaveOne & Reciproc & OneShape \\
\hline \multicolumn{4}{|l|}{ Volume $\left(\mathrm{mm}^{3}\right)$} \\
\hline Original & $1.92(0.60)$ & $2.05(0.65)$ & $1.87(0.49)$ \\
\hline Median (interquartile range) of increase & $1.03(0.65)$ & $0.95(0.55)$ & $0.90(0.59)$ \\
\hline Median (interquartile range) of increase (\%) & $58.52(24.36)^{A}$ & $40.78(27.39)^{A}$ & $35.09(24.61)^{\mathrm{A}}$ \\
\hline \multicolumn{4}{|l|}{ Surface Area $\left(\mathrm{mm}^{2}\right)$} \\
\hline Original & $15.84(1.81)$ & $16.52(2.61)$ & $15.93(2.94)$ \\
\hline Median (interquartile range) of increase & $3.39(1.78)$ & $3.11(2.08)$ & $3.75(1.82)$ \\
\hline Median (interquartile range) of increase (\%) & $32.02(15.65)^{\mathrm{A}}$ & $26.58(10.82)^{A}$ & $38.21(16.29)^{\mathrm{A}}$ \\
\hline \multicolumn{4}{|l|}{ SMI } \\
\hline Original & $2.70(0.27)$ & $2.56(0.25)$ & $2.68(0.20)$ \\
\hline Median (interquartile range) of increase & $0.18(0.13)$ & $0.07(0.10)$ & $0.41(0.16)$ \\
\hline Median (interquartile range) of increase (\%) & $5.17(5.00)^{A B}$ & $2.66(4.54)^{\mathrm{B}}$ & $19.15(7.54)^{\mathrm{A}}$ \\
\hline
\end{tabular}

The values followed by different letters in row from the Tukey-Test $(p<0.05)$.

foramen. The working length (WL) was established by subtracting $1 \mathrm{~mm}$ from where the file was just visible at the foramen. A glide path was created using a size 15 K-type file (Dentsply Sirona, Ballaigues, Switzerland) carried to the WL. All tested instruments were taken to the WL powered by an electric motor (X-Smart Plus; Dentsply Sirona, Ballaigues, Switzerland), according to the manufacturers' instructions. WaveOne Primary (Dentsply Sirona, Ballaigues, Switzerland) (size 25,.08 taper over the first $3 \mathrm{~mm}$ from apical tip) and Reciproc R25 (VDW, Munich, Germany) (size 25,.08 taper) were introduced into the canal until resistance was felt and then activated in reciprocating motion. The instruments were gently moved down until they reach the WL. One Shape instrument (Micro Mega, Besancon, France) (size 25,.06 taper) was used in continuous clockwise rotation motion at $400 \mathrm{rpm}$ and a torque of $4 \mathrm{~N} . \mathrm{cm}$ torque. In all groups, after three gentle in-and-out motion strokes in apical direction, the instrument was removed from the canal and cleaned, until the WL was reached. To avoid instrument fracture, one instrument was used to enlarge two canals only. Between each preparation step, irrigation was performed with disposable syringes and 30-G NaviTip needles (Ultradent, South Jordan, UT, USA) taken up to $2 \mathrm{~mm}$ short of the WL, using a total of $15 \mathrm{~mL}$ of $2.5 \% \mathrm{NaOCl}$ (Asfer, São Caetano do Sul, São Paulo, Brazil) per canal. A final rinse with $5 \mathrm{~mL}$ 17\% EDTA (Sigma-Aldrich, St
Louis, USA) (5 min), followed by $5 \mathrm{~mL}$ rinse with distilled water was performed. Then, canals were dried with absorbent paper points (Dentsply Sirona, Ballaigues, Switzerland), and the roots submitted to a postoperative micro-CT scan and reconstruction, applying the parameter settings mentioned previously.

\section{Micro-CT evaluation}

Images were reconstructed from the apex to the level of the cementoenamel junction (NRecon v1.6.4; Bruker), providing axial cross sections of the inner structure of the samples. CTAn v.1.14.4 software was used to measure volume (in $\mathrm{mm}^{3}$ ), surface area (in $\mathrm{mm}^{2}$ ), structure model index (SMI), perimeter (in $\mathrm{mm}$ ), area (in $\mathrm{mm}^{2}$ ), roundness, major diameter (in $\mathrm{mm}$ ), minor diameter (in $\mathrm{mm}$ ) of the root canals before and after preparation. The SMI is determined by an infinitesimal enlargement of the surface and is used to evaluate surface convexity in 3-dimensional structures ${ }^{31}$. 3D and 2-dimensional (2D) evaluation was performed for the full canal length. Moreover, all 2D data were analyzed by root thirds and a additional evaluation was performed for the major diameter and minor diameter for each $\mathrm{mm}$ of the root canal only for the untreated root canals. Cross-sectional root canal shape was determined by means of microcomputed tomography (micro-CT) with a mathematical calculation of roundness, which is represented by the formula $4 . \mathrm{A} /\left(\pi \cdot\left[\mathrm{d}_{\max }\right]^{2}\right)$, where ' $\mathrm{A}$ ' 
is the area and ' $\mathrm{d}_{\max }$ ' is the major diameter of the root canal $^{22}$. Comparison parameters were calculated by subtracting values obtained for treated canals with those obtained from untreated counterparts, thus determining the change $\%$ of the parameters. The major and minor diameters data evaluated at each $\mathrm{mm}$ of the root canal before preparation were used for linear regression analysis.

Canal transportation was assessed from centers of gravity that were calculated for each slice and connected along the z-axis with a fitted line in a crosssection, using CTAn software. Mean transportation (in $\mathrm{mm}$ ) was then calculated by comparing the centers of gravity before and after treatment of the coronal, middle, and apical thirds of the root canals.

Color-coded 3D models of the root canals, before and after preparation, were co-registered using automated image registration module of the DataViewer v.1.5.0 software (Bruker-microCT). Unprepared (green) and prepared (red) matched canals were qualitatively compared using CTVol v.2.2.1 software (Bruker-microCT).

Data were examined for normal distribution (Shapiro-Wilk test, $\mathrm{p}>0.05$ ) and homogeneity of variance (Levene test, $0>0.05$ ). Linear regression was used to evaluate the increase of the major and minor diameter of the root canal starting from the apical foramen. 2D parameters were analyzed by Two-way ANOVA in a split-plot arrangement with the plot represented by systems and the subplot represented by the root thirds, and 3D data by One-way ANOVA post hoc Tukey-Test (SPSS v17.0 for Windows; SPSS Inc., Chicago, USA). Significance level was set at $5 \%$.

\section{Results}

The results of the $3 \mathrm{D}$ analyses and canal transportation are shown in Tables 1 and 2, respectively. Regarding 3D parameters, the three file systems increased the surface area, volume and SMI after instrumentation of root canals. 3D analyses showed no significant differences between the groups for surface area $(p=0.128)$ and volume $(p=0.584)$, however, for the SMI statistical difference was found between Reciproc and OneShape $(p<0.05)$ (Table 1). No significant difference was observed between the file systems in canal transportation for coronal $(p=0.352)$, middle $(p=0.565)$ and apical $(p=0.480)$ thirds and for overall canal length $(p=0.640)$ (Table 2$)$. Reciproc and OneShape presented centralized preparation, especially in the apical region. The WaveOne group, showed canal transportation in the apical region.

The results of the 2D analyses are shown in Table 3. The biomechanical preparation significantly increased all measured parameters in all group. No statistical difference was found among groups for surface area, perimeter, roundness, and minor diameter ( $p>0.05)$. Overall, the percentage increase for the major diameter were significantly higher in the WaveOne and Reciproc groups when compared with the OneShape ( $p$ 0.05) for the coronal and middle thirds, as well as for he full root canal length. For the apical third there was no statistical difference between the studied groups.

The simple linear regression model showed that the major (Figure 1A) and minor diameters (Figure 1B) were significantly associated with the distance from the apical foramen $(p<0.001)$, with a determination coefficient of 0.233 and 0.269 respectively. A progressive increase was observed in each millimeter of the root canal of 0.0672 and 0.0337 for the major and minor diameter respectively (Figure 1).

Based on the reconstruction and superposition of the preoperative (green) and postoperative (red) canal surfaces (Figure 2), changes were observed in the canals in all groups. None of the instruments used were able to touch all the walls of the root canal.

\section{Discussion}

With the constant evolution of the mechanized systems and consequent optimization of the

Table 2. Means (SD) of transportation in different canal areas.

\begin{tabular}{lccc}
\hline \multirow{2}{*}{ Canal Area } & \multicolumn{3}{c}{ Systems } \\
\cline { 2 - 4 } & Wave One & Reciproc & OneShape \\
\hline Coronal & $0.07 \pm 0.04^{\mathrm{A}}$ & $0.07 \pm 0.03^{\mathrm{A}}$ & $0.09 \pm 0.03^{\mathrm{A}}$ \\
Middle & $0.07 \pm 0.02^{\mathrm{A}}$ & $0.05 \pm 0.04^{\mathrm{A}}$ & $0.07 \pm 0.03^{\mathrm{A}}$ \\
Apical & $0.12 \pm 0.05^{\mathrm{A}}$ & $0.10 \pm 0.05^{\mathrm{A}}$ & $0.10 \pm 0.05^{\mathrm{A}}$ \\
Total & $0.09 \pm 0.04^{\mathrm{A}}$ & $0.08 \pm 0.04^{\mathrm{A}}$ & $0.09 \pm 0.04^{\mathrm{A}}$ \\
\hline
\end{tabular}

The uppercase letters indicates the statistical difference between columns from the Tukey-Test $(p<0.05)$. 


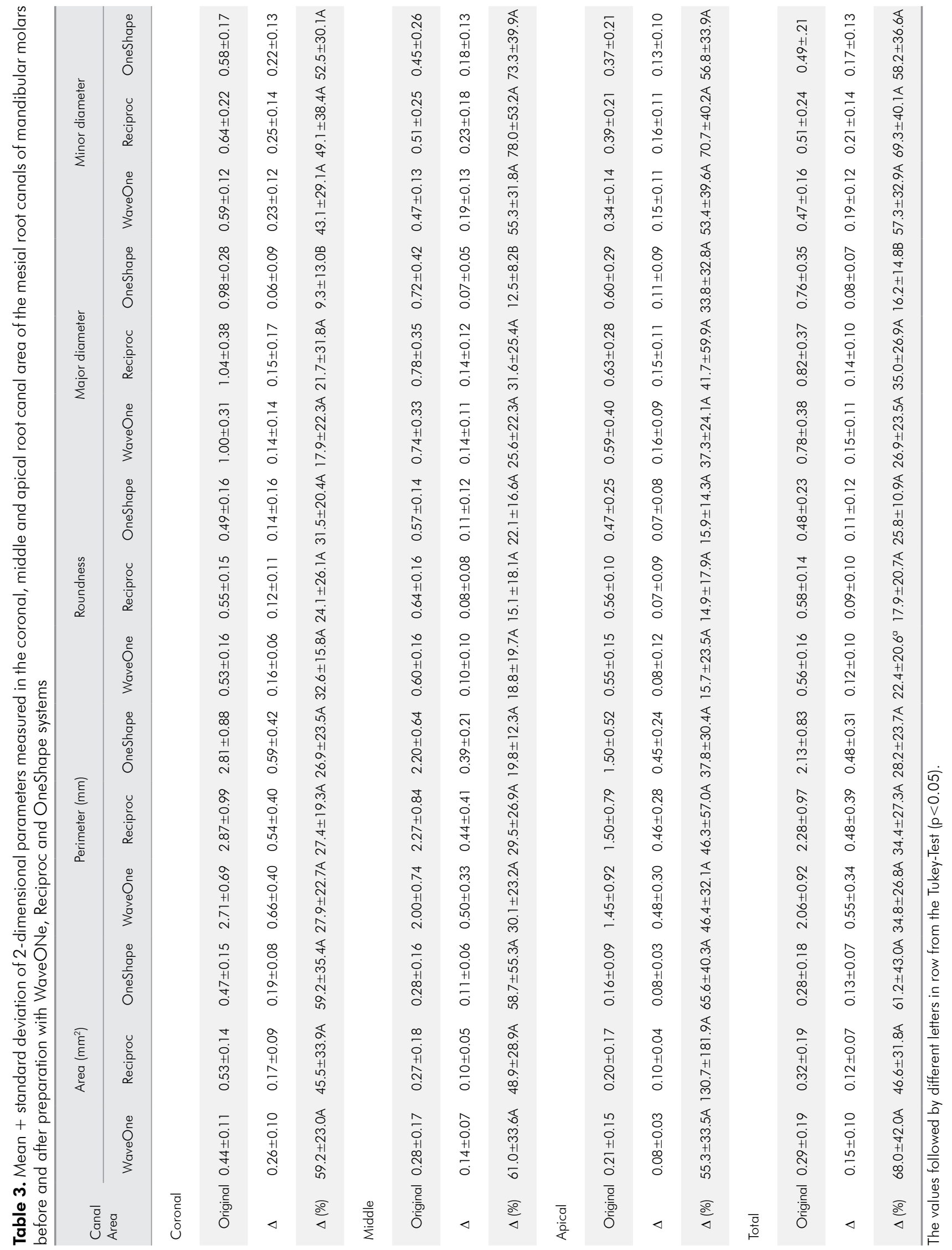



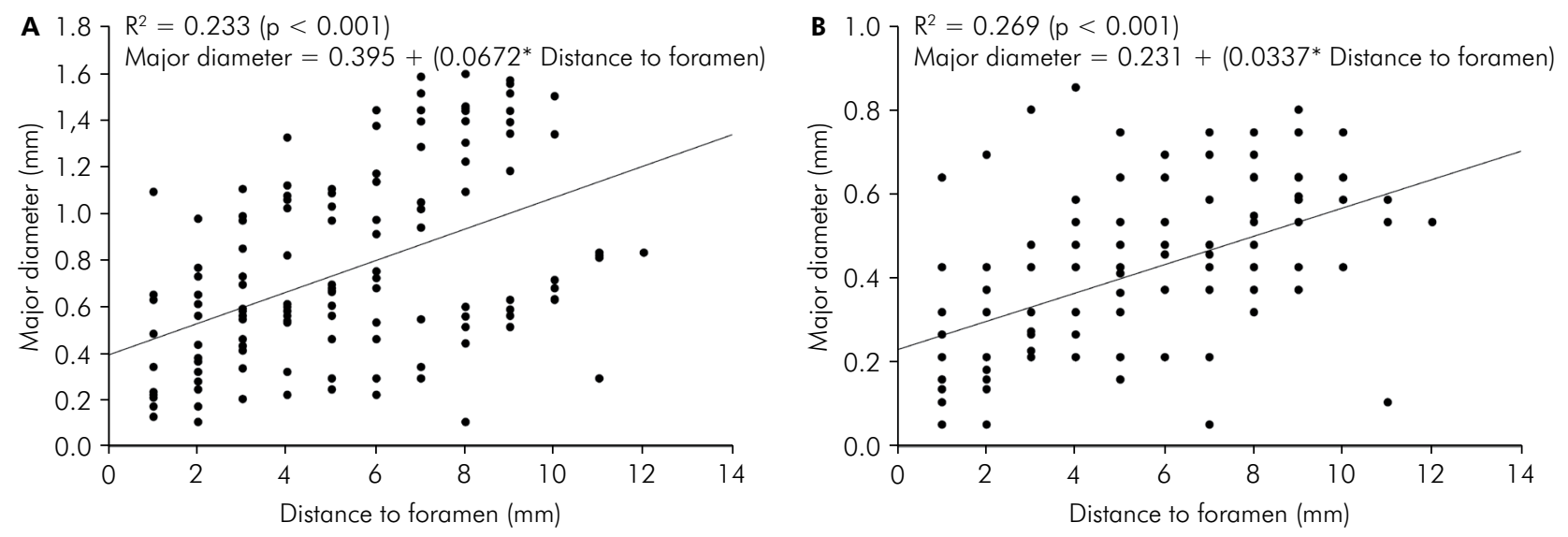

Figure 1. Relationship between major diameter (A) and minor diameter (B) with the distance from the apical foramen.
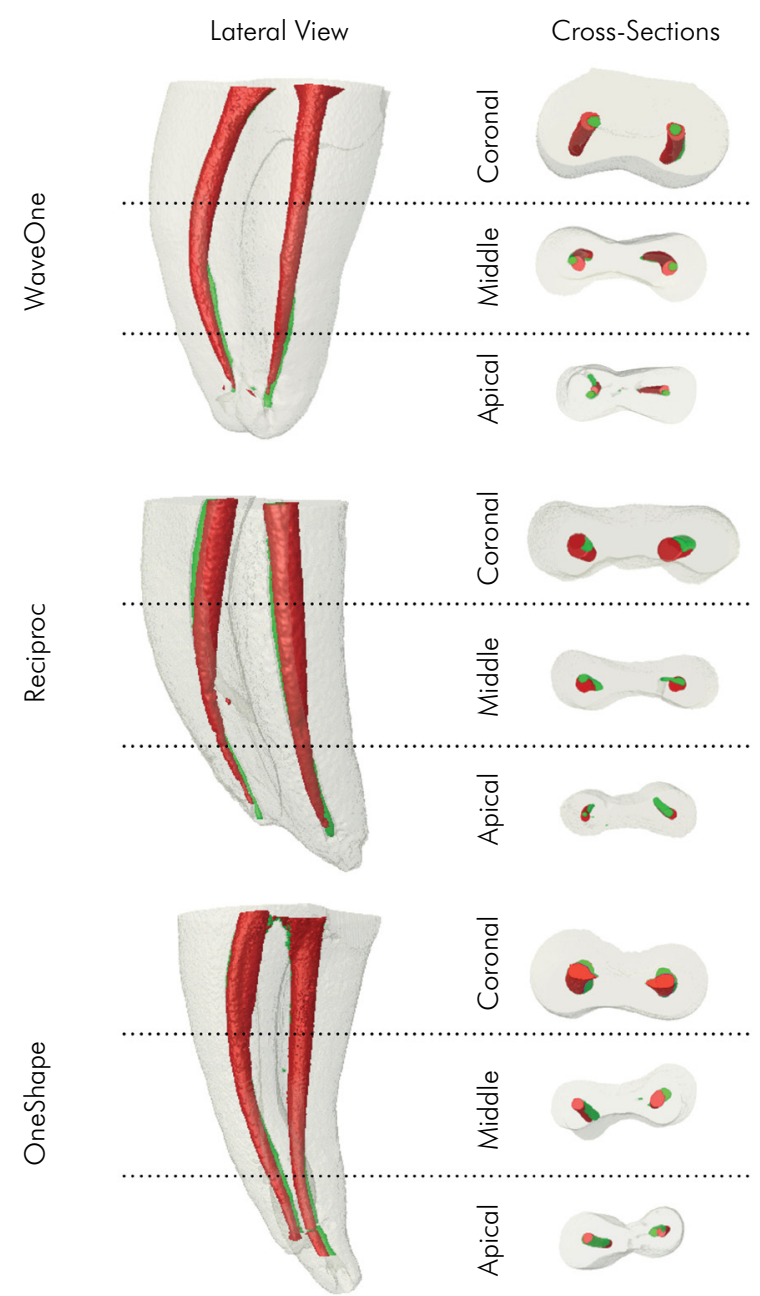

Figure 2. Lateral view of representative 3-dimensional reconstructions of the internal anatomy of superimposed mesial roots of a mandibular molar in each experimental group before (green) and after (red) canal preparation. Representative cross sections of the superimposed root canals before (green) and after (red) preparation at the coronal, middle, and apical thirds.

preparation of the root canal, especially in teeth with anatomical challenges, it is important to verify the impact of different single instrument systems in the preparation of root canals with moderate curvature.

The literature shows different methods to evaluate the effects generated in the root canal after the biomechanical preparation. Among them, the micro-CT is a method that allows the bi- dimensional and three-dimensional evaluation of the root canal morphology before and after the instrumentation, non-destructively and with a high resolution. ${ }^{14,16,23,24,25}$

An important aspect in the methodology used in the present study can be found in the samples selection and standardization, in which mesial roots of mandibular molars, presenting two independent root canals with curvature radius between 4 and $8 \mathrm{~mm}$ and angle of $10^{\circ}$ to $20^{\circ}$ were selected. According to De-Deus ${ }^{26}$ a careful sample selection and standardization allows the formation of balanced experimental groups, minimizing the critical effect of the root canal anatomy.

In all the evaluated systems, a single instrument with a final diameter of 25 was used, following the manufacturers recommendations for the instrumentation of curved root canals. However, the evaluated instruments have different tapers, the OneShape instrument with 0.06 and the Reciproc and WaveOne with $0.08 .^{18}$

The results showed that there was no statistical difference between the tested instruments regarding the changes in area, perimeter, canal transportation, volume, and surface area after root canal preparation. 
In addition, iatrogenic defects such as steps, zips, and perforations of the root canal were not observed. These results corroborate previous studies that demonstrate the effectiveness and safety of the Reciproc, WaveOne and OneShape systems in the preparation of curved root canals. ${ }^{11,12,13,14,15,16,17}$ Santa-Rosa et al. ${ }^{19}$ when comparing WaveOne and OneShape single-file systems in the preparation of mesiobuccal root canals of maxillary molars with severe curvatures found similar canal transportation between groups and minor changes in the canal curvature, corroborating with the results of the present study.

In contrast, Saber et al. ${ }^{18}$ when using X-ray analysis compared the preparation of severe curved root canals, using WaveOne, Reciproc and OneShape, and observed a greater apical transportation when using the OneShape system. Similarly, Dhingra et al. ${ }^{13}$ showed that WaveOne preserved canal shape better than OneShape file, however the authors used Endo Training Blocks and pre and post-digital images as a method. The difference found between Saber et al. ${ }^{18}$ and Dhingra et al. ${ }^{13}$ results and the results of the present study may be related to the employed methods. In the present study the micro-CT was used, which is a high acuity tool that allows non-invasive and non-destructive evaluation with the possibility of overlapping the images of the teeth in the different sequential stages of the Endodontic treatment. ${ }^{20,27}$

The qualitative analysis showed that none of the instruments used in the present study were able to touch all the walls of the root canal. These results can be related to two factors: the anatomy of the root canal and the instrument taper. The analysis of the two-dimensional roundness morphometric data presented values between 0.45 and 0.62 (Table 3), in addition, simple linear regression analysis showed that the root canal taper varies differently between the major (0.0673) and minor diameter (0.0337). Thereby, considering that instruments with.08 and.06 tapers were used, it is justified that these instruments do not act on all walls along the root canal; thus, the instruments promote a greater touch area on the minor diameter and a smaller touch area on the major diameter.

The values of roundness can range from 0 to 1 , where 0 means straight and 1 means a perfect circle. ${ }^{20,28}$ Thus, in the present study, the roundness and taper data characterize the root canals as ovals in all the thirds, ${ }^{22}$ which represents difficulty during instrumentation and cleaning, since the polar areas resulting from flattening hamper the action of the instruments. ${ }^{20,29}$ These data may also explain the results of previous studies that claim that approximately $20-35 \%$ of the area of curved root canals of mandibular molars remained untouched after biomechanical preparation. ${ }^{16,30}$

The structure of an object is characterized as 0 for an ideal plate to 4 for a perfect ball., ${ }^{3,31}$ The three-dimensional analysis represented by the SMI showed a greater change in root canal shape after preparation with the OneShape when compared to the Reciproc system. It is suggested that this difference between the two systems may be related to instrument design. While the cross section of Reciproc system is S-shaped with sharp blades along the whole active part of the instrument, OneShape instrument is characterized by a modified triangular cross section with three sharp cutting edges in the apical and middle regions and an S-shaped design with two cutting edges near the shaft. ${ }^{8,11}$

When evaluating the action of the instrument systems in the different thirds of the root canal, it was evidenced that the canal transportation was significantly higher in the apical third compared to the cervical and middle thirds. In the present study, the instruments were used according to manufacturer's recommendations, without conducting a prior cervical preparation. The literature shows that the presence of interference in the cervical region results in accidents and major changes in apical third, ${ }^{32}$ and that performing a cervical pre-flaring prior to the use of single file systems is critical to the maintenance of root canal, avoiding canal transportation in the middle and apical thirds. ${ }^{25,33}$ During the biomechanical preparation of curved canals, the maintenance of the root canal shape and direction is directly related to the success of endodontic treatment. ${ }^{25,34,35}$

\section{Conclusion}

In general, the instruments behaved similarly in the preparation of curved root canals of mandibular molars regarding the evaluated parameters. 


\section{Acknowledgement}

We gratefully acknowledge financial supported by the Coordination for the Improvement of Higher

\author{
Education Personnel (CAPES-Brazil - process \\ $\mathrm{n}^{\circ}$ 33002029032P4) and The São Paulo Research \\ Foundation (FAPESP - process n $\left.{ }^{\circ} 2018 / 14450-1\right)$.
}

\section{References}

1. Min Y, Ma JZ, Shen Y, Cheung GS, Gao Y. A micro-computed tomography study of the negotiation and anatomical feature in apical root canal of mandibular molars. Scanning. 2016 Nov;38(6):819-24. https://doi.org/10.1002/sca.21331

2. Keleş A, Keskin C. Apical root canal morphology of mesial roots of mandibular first molar teeth with vertucci Type II configuration by means of micro-computed tomography. J Endod. 2017 Mar;43(3):481-5. https://doi.org/10.1016/i.joen.2016.10.045

3. Almeida BC, Ormiga F, Araújo MC, Lopes RT, Lima IC, Santos BC, et al. Influence of heat treatment of nickel-titanium rotary endodontic instruments on apical preparation: a micro-computed tomographic study. J Endod. 2015 Dec;41(12):2031-5. https://doi.org/10.1016/i.joen.2015.09.001

4. Pedullà E, Genovesi F, Rapisarda S, La Rosa GR, Grande NM, Plotino G, et al. Effects of 6 single-file systems on dentinal crack formation. J Endod. 2017 Mar;43(3):456-61. https://doi.org/10.1016/i.joen.2016.10.038

5. Zanesco C, Só MV, Schmidt S, Fontanella VR, Grazziotin-Soares R, Barletta FB. Apical transportation, centering ratio, and volume increase after manual, rotary, and reciprocating instrumentation in curved root canals: analysis by micro-computed tomographic and digital subtraction radiography. J Endod. 2017 Mar;43(3):486-90. https://doi.org/10.1016/i.joen.2016.11.006

6. Paqué F, Ganahl D, Peters OA. Effects of root canal preparation on apical geometry assessed by micro-computed tomography. J Endod. 2009 Jul;35(7):1056-9. https://doi.org/10.1016/i.joen.2009.04.020

7. Abou-Rass M, Frank AL, Glick DH. The anticurvature filing method to prepare the curved root canal. J Am Dent Assoc. 1980 Nov;101(5):792-4. https://doi.org/10.14219/jada.archive.1980.0427

8. Bürklein S, Schäfer E. Apically extruded debris with reciprocating single-file and full-sequence rotary instrumentation systems. J Endod. 2012 Jun;38(6):850-2. https://doi.org/10.1016/i.joen.2012.02.017

9. Gergi R, Arbab-Chirani R, Osta N, Naaman A. Micro-computed tomographic evaluation of canal transportation instrumented by different kinematics rotary nickel-titanium instruments. J Endod. 2014 Aug;40(8):1223-7. https://doi.org/10.1016/i.joen.2014.01.039

10. Yared G. Canal preparation using only one Ni-Ti rotary instrument: preliminary observations. Int Endod J. 2008 Apr;41(4):339-44. https://doi.org/10.1111/j.1365-2591.2007.01351.x

11. Bürklein S, Benten S, Schäfer E. Shaping ability of different single-file systems in severely curved root canals of extracted teeth. Int Endod J. 2013 Jun;46(6):590-7. https://doi.org/10.1111/iej.12037

12. Capar ID, Ertas H, Ok E, Arslan H, Ertas ET. Comparative study of different novel nickel-titanium rotary systems for root canal preparation in severely curved root canals. J Endod. 2014 Jun;40(6):852-6. https://doi.org/10.1016/j.joen.2013.10.010 PMID:24862716

13. Dhingra A, Kochar R, Banerjee S, Srivastava P. Comparative evaluation of the canal curvature modifications after instrumentation with One Shape rotary and Wave One reciprocating files. J Conserv Dent. 2014 Mar;17(2):138-41. https://doi.org/10.4103/0972-0707.128049

14. McRay B, Cox TC, Cohenca N, Johnson JD, Paranipe A. A micro-computed tomography-based comparison of the canal transportation and centering ability of ProTaper Universal rotary and WaveOne reciprocating files. Quintessence Int. 2014 Feb;45(2):101-8. https://doi.org/10.3290/i.qi.a30998

15. Agarwal RS, Agarwal J, Jain P, Chandra A. Comparative analysis of canal centering ability of different single file systems using cone beam computed tomography: an in-vitro study. J Clin Diagn Res. 2015 May;9(5):ZC06-10. https://doi.org/10.7860/JCDR/2015/12097.5863

16. Gergi R, Osta N, Bourbouze G, Zgheib C, Arbab-Chirani R, Naaman A. Effects of three nickel titanium instrument systems on root canal geometry assessed by micro-computed tomography. Int Endod J. 2015 Feb;48(2):162-70. https://doi.org/10.1111/iej.12296

17. Marceliano-Alves MF, Sousa-Neto MD, Fidel SR, Steier L, Robinson JP, Pécora JD, et al. Shaping ability of single-file reciprocating and heattreated multifile rotary systems: a micro-CT study. Int Endod J. 2015 Dec;48(12):1129-36. https://doi.org/10.1111/iej.12412

18. Saber SE, Nagy MM, Schäfer E. Comparative evaluation of the shaping ability of WaveOne, Reciproc and OneShape single-file systems in severely curved root canals of extracted teeth. Int Endod J. 2015 Jan;48(1):109-14. https://doi.org/10.1111/iej.12289

19. Santa-Rosa J, Sousa-Neto MD, Versiani MA, Nevares G, Xavier F, Romeiro K, et al. Shaping ability of single-file systems with different movements: a micro-computed tomographic study. Iran Endod J. 2016;11(3):228-33. https://doi.org/10.7508/iej.2016.03.016

20. Versiani MA, Leoni GB, Steier L, De-Deus G, Tassani S, Pécora JD, et al. Micro-computed tomography study of oval-shaped canals prepared with the self-adjusting file, Reciproc, WaveOne, and ProTaper universal systems. J Endod. 2013 Aug;39(8):1060-6. https://doi.org/10.1016/i.joen.2013.04.009

21. Schneider SW. A comparison of canal preparations in straight and curved root canals. Oral Surg Oral Med Oral Pathol. 1971 Aug;32(2):271-5. https://doi.org/10.1016/0030-4220(71)90230-1 
22. Pereira RD, Brito-Júnior M, Leoni GB, Estrela C, Sousa-Neto MD. Evaluation of bond strength in single-cone fillings of canals with different cross-sections. Int Endod J. 2017 Feb;50(2):177-83. https://doi.org/10.1111/iej.12607

23. Peters OA, Schönenberger K, Laib A. Effects of four Ni-Ti preparation techniques on root canal geometry assessed by micro computed tomography. Int Endod J. 2001 Apr;34(3):221-30. https://doi.org/10.1046/i.1365-2591.2001.00373.x

24. Ordinola-Zapata R, Bramante CM, Duarte MA, Cavenago BC, Jaramillo D, Versiani MA. Shaping ability of reciproc and TF adaptive systems in severely curved canals of rapid microCT-based prototyping molar replicas. J Appl Oral Sci. 2014 Nov-Dec;22(6):509-15. https://doi.org/10.1590/1678-775720130705

25. Amaral ROJF, Leonardi DP, Gabardo MC, Coelho BS, Oliveira KV, Baratto Filho F. Influence of cervical and apical enlargement associated with the waveone system on the transportation and centralization of endodontic preparations. J Endod. 2016 Apr;42(4):626-31. https://doi.org/10.1016/i.joen.2015.12.005

26. De-Deus G. Research that matters - root canal filling and leakage studies. Int Endod J. 2012 Dec;45(12):1063-4. https://doi.org/10.1111/j.1365-2591.2012.02104.x

27. Versiani MA, Pécora JD, Sousa-Neto MD. Microcomputed tomography analysis of the root canal morphology of single-rooted mandibular canines. Int Endod J. 2013 Sep;46(9):800-7. https://doi.org/10.1111/iej.12061

28. Leoni GB, Versiani MA, Pécora JD, Sousa-Neto MD. Micro-computed tomographic analysis of the root canal morphology of mandibular incisors. J Endod. 2014 May;40(5):710-6. https://doi.org/10.1016/i.joen.2013.09.003

29. Barbizam JV, Fariniuk LF, Marchesan MA, Pecora JD, Sousa-Neto MD. Effectiveness of manual and rotary instrumentation techniques for cleaning flattened root canals. J Endod. 2002 May;28(5):365-6. https://doi.org/10.1097/00004770-200205000-00004

30. Paqué F, Zehnder M, De-Deus G. Microtomography-based comparison of reciprocating single-file F2 ProTaper technique versus rotary full sequence. J Endod. 2011 Oct;37(10):1394-7. https://doi.org/10.1016/i.joen.2011.06.031

31. Peters $O A$, Laib A, Rüegsegger P, Barbakow F. Three-dimensional analysis of root canal geometry by high-resolution computed tomography. J Dent Res. 2000 Jun;79(6):1405-9. https://doi.org/10.1177/00220345000790060901

32. Abou-Rass M, Jastrab RJ. The use of rotary instruments as auxiliary aids to root canal preparation of molars. J Endod. 1982 Feb;8(2):78-82. https://doi.org/10.1016/S0099-2399(82)80262-8

33. Leonardi DP, Schramm CA, Giovanini AF, Silveira CM, Tomazinho FSF, Baratto-Filho F. Influence of prior cervical enlargement on apical cleaning using single file. Bull Tokyo Dent Coll. 2015;56(2):85-91. https://doi.org/10.2209/tdcpublication.56.85

34. Peters OA. Current challenges and concepts in the preparation of root canal systems: a review. J Endod. 2004 Aug;30(8):559-67. https://doi.org/10.1097/01.DON.0000129039.59003.9D

35. Schäfer E, Erler M, Dammaschke T. Comparative study on the shaping ability and cleaning efficiency of rotary Mtwo instruments. Part 2. Cleaning effectiveness and shaping ability in severely curved root canals of extracted teeth. Int Endod J. 2006 Mar;39(3):203-12. https://doi.org/10.1111/j.1365-2591.2006.01075.x 